\title{
Patient-centred communication: a sophisticated procedure
}

\section{Wendy Levinson}

The Institute of Medicine identifies patient-centred care as one of the essential elements of high quality care. ${ }^{1}$ They define patient-centred care as 'respecting and responding to patients' wants, needs and preferences, so that patients can make choices in their care that best fit their individual circumstances'. Studies demonstrate that patient-centred care is associated with improved healthcare outcomes, particularly in patients with chronic diseases. ${ }^{2-8}$ It seems as if it would be both important and easy to deliver this kind of care. But, in fact, it is very difficult to do well.

Patient-centred care requires physicians and other healthcare providers to have the communication skills to elicit patients' true wishes and to recognise and respond to both their needs and their emotional concerns. As much as any technical skill, communication is a sophisticated procedure-one that needs to be taught and honed throughout one's career.

Patients assess the quality of their care largely through their experiences of talking with their physicians. When patients feel that the physicians listen carefully, understand their needs and provide information in a clear fashion, they are most likely to be satisfied with their care. As in the article by Fossli Jensen et $a l^{9}{ }^{9}$ most patients who experience this type of care will rate the physician highly on

Correspondence to Dr Wendy Levinson, Sir John and Lady Eaton Professor and Chair, Department of Medicine, University of Toronto, Suite 3-805,

R. Fraser Elliott Building, 190 Elizabeth Street, Toronto, ON M5G 2C4, Canada;

wendy.levinson@utoronto.ca any type of patient satisfaction questionnaire.That said, all patient satisfaction measurement tools tend to generate highly skewed results, with patients assigning highly positive ratings to most clinical encounters. However, when patients feel the physician rushed through the encounter and did not give them enough information, they report dissatisfaction with their care and more frequently lodge formal complaints or even seek legal recourse when poor outcomes also occur. Stories abound in the lay press about breakdowns in communication between well-intentioned physicians and bitterly disappointed patients. In short, patients place great value on the quality of physician communication.

With ample evidence of the importance of communication to patient outcomes, satisfaction with care and even medicolegal risk, never mind the intrinsic value for patients, one would think communication skills would receive considerable attention-during medical training and perhaps even ongoing assessment and improvement as part of continuous professional development activities. In fact, the skills of patient-centred communication are rarely taught despite long-standing calls for attention to this issue. ${ }^{10} 11$

Medical students learn to take a history, but this teaching focuses primarily on the basic skills of collecting information necessary to make a diagnosis. During postgraduate training, residents further develop their diagnostic and management skills of caring for patients by experience and supervision. But rarely do trainees receive instruction in communication or specific feedback on their performance as communicators. Furthermore, almost no opportunities exist for practicing physicians to learn new communication skills. Even if such opportunities did exist, physicians do not receive systematic feedback on their interactions with patients. Consequently, most physicians do not realise that they could improve these skills.

This lack of attention to learning new communication skills differs markedly from the common practice of physicians who continue to hone their knowledge base in medical science and, in some specialities, to learn new technical procedures-like new non-invasive endoscopy or percutaneous cardiac techniques. Physicians recognise the acquisition of new information and technical skills as part of their professional activities over their career lifetime. By contrast, they generally do not regard learning how to communicate effectively in challenging situations-like helping patients make complex choices in circumstances of medical uncertainly, disclosing medical errors or breaking bad and distressing news-as part of their continuing professional development. Most physicians assume they already do these things well.

Fossli Jensen et at find that both patients and expert assessors of communication identified a handful of physicians as weak in their communication skills. Since patients rarely rate their physicians poorly, this group consists of fairly extreme outliers lacking fundamental communication skills. These physicians clearly need feedback and instruction. Most likely, they are unaware of their deficiencies-how would they be expected to know when their skills have most likely not been assessed since finishing their training (and possibly not even during training)? 
The authors suggest that not only 'outliers' but all physicians could benefit from communication training including some feedback on their skills. In the spirit of continuous quality improvement, all physicians could review their performance on their routine communication and develop a quality improvement plan in some areas. All physicians can assess their skills in routine aspects of patient-centred communication: fostering healing relationships, exchanging information, responding to emotions, managing uncertainty, making decisions and enabling selfmanagement. Additionally, they can hone higher level skills like disclosing errors-most physicians have never learned skills in this area. ${ }^{101213}$ This type of learning best occurs using some method of observation, feedback and selfreflection. Like learning any other type of procedure, communication skills require practice, feedback and repeated attempts to improve. A recent review ${ }^{10}$ suggests methods to provide training for different levels of physician learners.

How can we best measure patientcentred communication? Multiple methods exist, including: direct observation by teachers, videotape or audiotape analysis by experts, standardised patients to test specific skills, and monitoring of both patient satisfaction and patient complaints. ${ }^{11} 14$ However, it is logistically difficult to videotape visits and direct observation is expensive. The most commonly used method is measurement of the patient experience based on ratings and the most common of these is the Consumer Assessment of Healthcare Providers and Systems (CAHPS) survey. ${ }^{15}$ The CAHPS patient survey includes six discrete items, each rating an aspect of communication (eg, 'During your most recent visit, did this doctor give you easy to understand instructions...?'), and the overall satisfaction item used by Fossli Jensen et $a l^{9}$
CAHPS research demonstrates that 45 questionnaires per physician are necessary to achieve a physician level reliability coefficient of $0.70-$ a level of reliability needed for any high stakes evaluation like public reporting or physician payment. $^{15}$ However, lower numbers of surveys might be acceptable, despite lower physician level reliability, for formative feedback to physicians. Additionally, ratings on the individual CAHPS items may provide feedback about specific communication skills for quality improvement purposes. In fact, this assessment method is used by the certifying boards in the USA as part of the Maintenance of Certification process and physicians can elect to undertake practice improvement based on patient satisfaction ratings.

Physicians sometimes express the concern that effective communication takes time-something that is in short supply with the pressure to see more patients in a day. Without question, effective communication requires time. How can one tell a patient he or she has a new diagnosis of cancer and then hurry out of the room? Listening to patients' concerns, addressing patients' worries and helping patients decide whether or not to undergo risky procedures all require time. However, time alone does not ensure effective communication-skills are essential.

If we seek to provide the highest quality of care to our patients, we need to learn these skills and practice them routinely. We need to apply the same quality improvement strategies to honing these skills as we do to other aspects of our practice. Patient questionnaires are one source of feedback that can help us to improve. Video recordings, ${ }^{16}$ periodic observed interactions with standardised patients ${ }^{17}$ and the use of multisource feedback ${ }^{18}$ provide other tools for assessment. Whatever tools we use, we should collect data on a regular basis, analyse the results compared with peers and keep improving-forever.

Competing interests None.

Provenance and peer review Commissioned; internally peer reviewed.

Published Online First 19 August 2011

BMJ Qual Saf 2011;20:823-825.

doi:10.1136/bmjqs-2011-000323

\section{REFERENCES}

1. Institute of Medicine. Committee on Quality of Health Care in America. Crossing the Quality Chasm: A New Health System for the 21st Century. Washington, DC: National Academy Press, 2001.

2. Epstein RM, Street RL. Patient-Centered Communication in Cancer Care: Promoting Healing and Reducing Suffering. Bethesda, MD: National Cancer Institute, $\mathrm{NIH}, 2007$.

3. Greenfield S, Kaplan S, Ware JE Jr. Expanding patient involvement in care. Effects on patient outcomes. Ann Intern Med 1985; 102:520-8.

4. Mead N, Bower P. Measuring patient-centredness: a comparison of three observation-based instruments. Patient Educ Couns 2000;39:71-80.

5. Ong LM, de Haes JC, Hoos AM, et al. Doctor-patient communication: a review of the literature. Soc Sci Med 1995;40:903-18.

6. Safran DG, Taira DA, Rogers WH, et al. Linking primary care performance to outcomes of care. J Fam Pract 1998;47:213-20.

7. Stewart M, Brown JB, Donner A, et al. The impact of patient-centered care on outcomes. J Fam Pract 2000;49:796-804

8. Epstein RM, Franks $\mathrm{P}$, Fiscella $\mathrm{K}$, et al. Measuring patient-centered communication in patient-physician consultations: theoretical and practical issues. Soc Sci Med 2005;61:1516-28.

9. Fossli Jensen B, Dahl FA, Safran DG, et al. The ability of a behaviour specific patient questionnaire to identify poorly performing doctors. BMJ Qual Saf 2011;20:885-93.

10. Levinson W, Lesser CS, Epstein RM. Developing physician communication skills for patient-centered care. Health Aff (Millwood) 2010;29:1310-18.

11. Levinson W, Pizzo PA. Patient-physician communication: it's about time. JAMA 2011;305:1802-3.

12. Chan DK, Gallagher TH, Reznick R, et al. How surgeons disclose medical errors to patients: a study using standardized patients. Surgery 2005;138:851-8.

13. Rao JK, Anderson LA, Inui TS, et al. Communication interventions make a difference in conversations between physicians and patients: a systematic review of the evidence. Med Care 2007;45:340-9.

14. Epstein RM, Fiscella K, Lesser CS, et al. Why the nation needs a policy push on patient-centered health care. Health Aff (Millwood) 2010;29:1489-95.

15. Agency for Healthcare Research and Quality. CAHPS ${ }^{\mathbb{B}}$ Clinician \& Group Survey and Reporting Kit 2008. 
https://www.cahps.ahrq.gov/cahpskit/CG/ CGChooseQX.asp (accessed 11 Aug 2011).

16. Fassaert $\mathrm{T}$, van Dulmen $\mathrm{S}$, Schellevis $\mathrm{F}$, et al. Active listening in medical consultations: development of the Active Listening Observation Scale
(ALOS-global). Patient Educ Couns 2007;68:258-64.

17. Ram P, van der Vleuten $C$, Rethans JJ, et al. Assessment of practicing family physicians: comparison of observation in a multiple-station examination using standardized patients with observation of consultations in daily practice. Acad Med 1999;

74:62-9.

18. Lockyer J. Multisource feedback in the assessment of physician competencies. $J$ Contin Educ Health Prof 2003; 23:4-12.

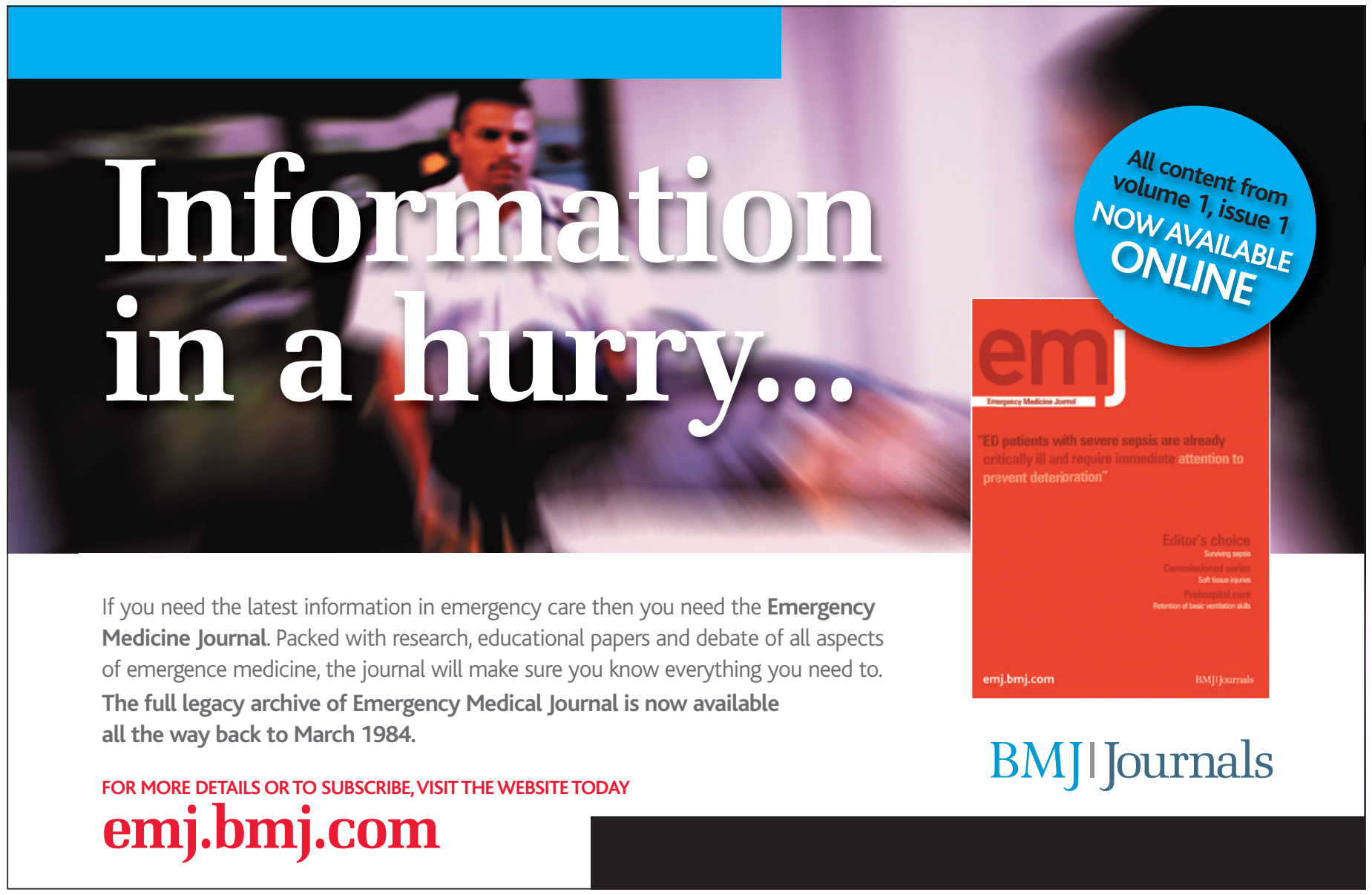

